\title{
A case of self-inflicted craniocerebral penetrating injury
}

\author{
G James, C J Blakeley, K Hashemi, K Channing, M Duff
}

Emerg Med J 2006;23:e32 (http://www.emjonline.com/cgi/content/full/23/5/e32). doi: 10.1136/emj.2005.032284

A 44 year old man was referred to the accident and emergency department by the psychiatric services, having claimed to have hammered several nails through his skull over a three month period. The patient had a long history of depression, personality disorder, and previous deliberate self-harm. He had remained well throughout this period and had been cleaning the wounds with weak antiseptic on a regular basis. He had concealed the injuries by wearing a hat. Two days prior to admission he had inserted a much larger $12.7 \mathrm{~cm}$ (5 inch) masonry nail and had developed left sided weakness and unsteadiness of gait.

Examination showed that the patient remained well with no evidence of infection in the central nervous system. Neurological examination revealed a mild left sided weakness (4/5 Medical Research Council (MRC) scale) affecting both the arm and leg. The patient was fully alert and orientated and conversed normally. Inspection of the scalp revealed a large masonry nail protruding from the scalp with several other healed puncture wounds. Plain skull $x$ rays revealed a total of ten $5 \mathrm{~cm}$ nails and a larger, $12.7 \mathrm{~cm}$ masonry nail penetrating the skull (see figs 1 and 2). A computed tomography (CT) scan was performed, which despite considerable artefact confirmed that the nails had penetrated the brain substance (fig 3). The patient was later transferred to the local neurosurgical unit for further management where, after angiography, all the nails were removed under general anaesthetic. He subsequently made an uneventful recovery.

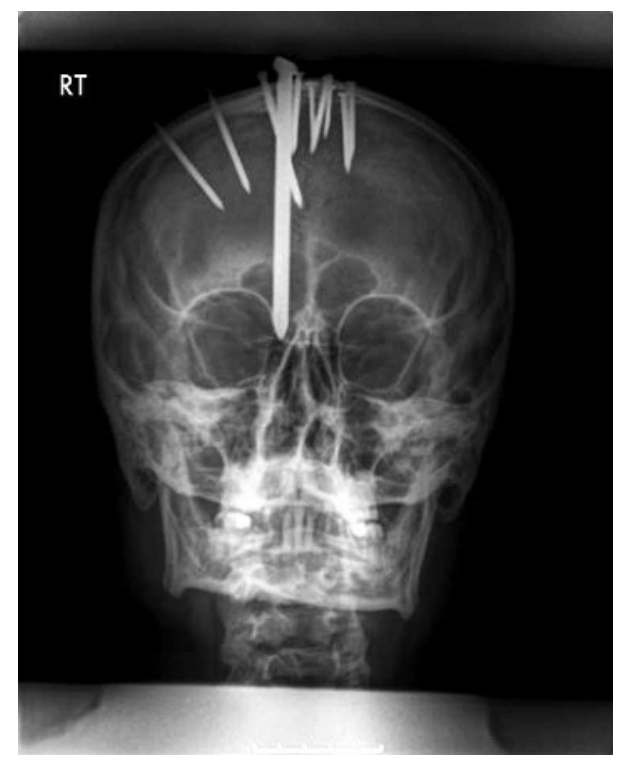

Figure 1 Anteroposterior skull $x$ ray of a 44 year old man showing several nails inserted in the skull.

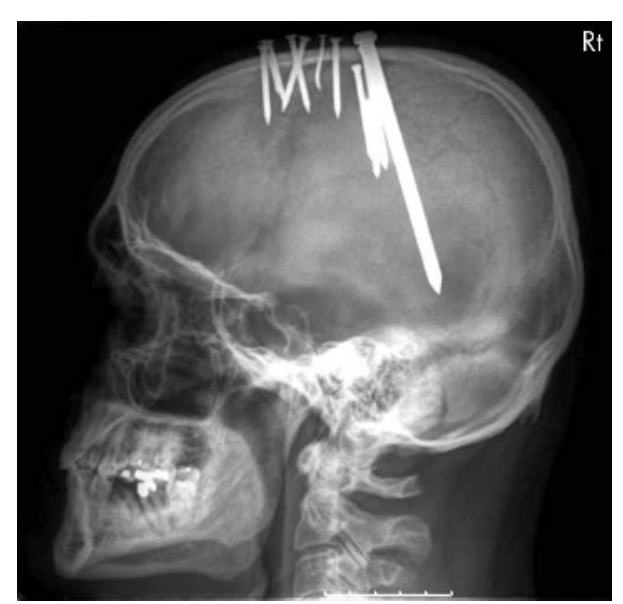

Figure 2 Lateral skull $x$ ray of the same patient.

\section{DISCUSSION}

High velocity penetrating craniocerebral injuries are becoming increasingly common in the UK with the proliferation of firearms. However, low velocity penetrating injuries such as stabbings or, as in our case, deliberate self-harm, are less common. There are a few case reports in the literature reporting similar self-inflicted craniocerebral injuries, caused by directly hammering of the nail or with the use of nail guns. What is surprising is that in the majority of cases there is little compromise of the patient's clinical state. In one case ${ }^{1}$ a nail remained in situ for three years before neurological symptoms developed and in a second report ${ }^{2}$ a patient was found with 11 nails penetrating the skull with no obvious neurological or vascular deficit. It is likely that this lack of permanent neurological deficit is a reflection of the low velocity, low energy nature of the injury, in that the nails are hammered in by a series of blows. Another potential source of

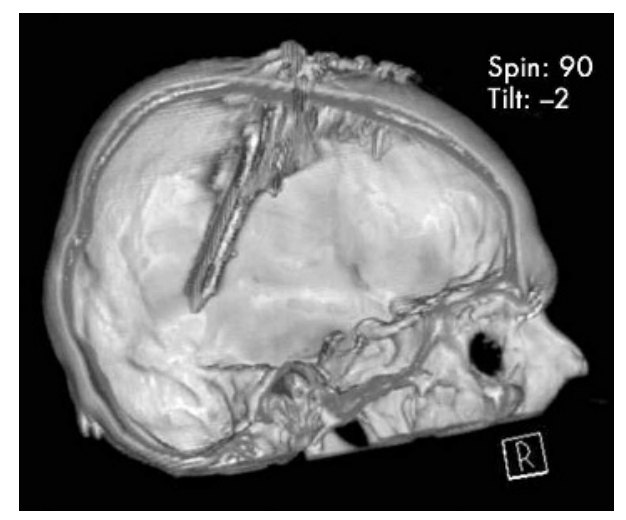

Figure 3 Three-dimensional computed tomography reconstruction. 
morbidity is the introduction of infection into the central nervous system. In another series of three patients, ${ }^{3}$ one patient died of meningitis.

One more learning point in this case report is the need to take claims of deliberate self-harm seriously. Most of our patient's wounds had healed and it is conceivable that if all had closed, the clinician may have discounted the patient's claims.

\section{Authors' affiliations}

G James, C J Blakeley, K Hashemi, K Channing, M Duff, Emergency

Department, Mayday University Hospital, Croydon, London, UK

Competing interests: none declared
Correspondence to: C J Blakeley, Emergency Department, Mayday University Hospital, Croydon, London, UK; christopher.blakeley@ mayday.nhs.uk

Accepted for publication 29 November 2005

\section{REFERENCES}

1 Spennato $P$, Bocchetti A, Mirone $G$, et al. Double concentric craniotomy for a craniocerebral penetrating nail. Case report and technical note. Surg Neurol 2005;64:368-71

2 Salar G, Costella GB, Mottaran R, et al. Multiple craniocerebral injuries from penetrating nails. Case illustration. J Neurosurg 2004; 100:963.

3 Ohaegbulam SC, Ojukwu JO. Unusual craniocerebral injuries from nailing. Surg Neurol 1980;14:393-5. 